\title{
Síndrome Febril Indeterminada: O Repto do Internista
}

\section{Fever of Unknown Origin: The Internist's Challenge}

Mário Barbosa ${ }^{1}$

Autor Correspondente: Mário Barbosa [martb2008@gmail.com]

Rua Prof. João Cândido Oliveira n7 - $1^{\circ}$ Dto., 1750-230 Lisboa, Portugal

\section{RESUMO}

A síndrome febril indeterminada representa desde os primórdios da Medicina um desafio diagnóstico.

Os autores relatam o caso de um homem de meia-idade, aparentemente saudável, que praticava atividades ao ar livre, admitido na nossa Unidade para esclarecimento de quadro de febre arrastada, sem foco aparente, com mais de três semanas de evolução até ao diagnóstico definitivo.

Salientamos a importância da ecografia hepática no esclarecimento etiológico da síndrome febril indeterminada nos quadros com clínica frustre, e a inclusão da amebíase no diagnóstico diferencial quando o contexto epidemiológico o justifica.

PALAVRAS-CHAVE: Abcesso Hepático; Abcesso Hepático Amebiano; Febre de Causa Desconhecida.

\section{ABSTRACT}

Fever of unknown origin represents since the dawn of Medicine a diagnostic challenge.

The authors report the case of a middle-aged man, apparently healthy, that practiced outdoor activities, admitted to our ward due to a febrile syndrome, without a categorical source, which lasted more than three weeks until conclusive diagnosis. We emphasize the importance of liver ultrasound to clarify the etiology of fever of unknown origin in mild clinical cases, and the inclusion of amebiasis in the differential diagnosis when epidemiologically justified.

KEYWORDS: Fever of Unknown Origin; Liver Abscess; Liver Abscess, Amebic 


\section{INTRODUÇÃO}

As três principais causas gerais de febre sem foco aparente são as doenças infeciosas, as doenças autoimunes, as neoplasias, o que se traduz num vasto espectro de diagnósticos possíveis. O raciocínio clínico, sustentado numa anamnese minuciosa, é a linha orientadora para uma investigação etiológica judiciosa e precisa. O caso descrito ilustra a complexidade da abordagem da síndrome febril indeterminada.

\section{CASO CLÍNICO}

Apresentamos o caso de um homem de 59 anos, caucasiano, casado, guarda prisional reformado. Seguido em consulta de Urologia para esclarecimento de elevação do prostate-specific antigen (PSA), tendo realizado biópsia prostática cujo resultado anatomopatológico foi negativo para células neoplásicas. Medicado com Permixon ${ }^{\circledR}$. Negava alergias, antecedentes de tuberculose, relações sexuais de risco ou hábitos toxifílicos, ingestão de água não canalizada, assim como hábitos tabágicos. Consumia cerca de 20 a 30 g de etanol por dia. Negava viagens recentes ao estrangeiro e picada de artrópode. Praticava caça e tinha cães. Aparentemente saudável, até sete dias antes do internamento, altura em que inicia quadro de febre (temperatura máxima quantificada em $39^{\circ} \mathrm{C}$ ), mialgias e um episódio de lipotimia.

Nesse contexto recorreu ao Atendimento Permanente (AP) do Hospital CUF Torres Vedras em dezembro de 2014. Objetivamente não se observaram alterações dignas de registo, excetuando febre $\left(38,4^{\circ} \mathrm{C}\right)$.

Das análises a salientar: leucocitose com neutrofilia (leucócitos: 18 400/mL com 85,1\% de neutrófilos), PCR: 27,68 mg/dL e urina II com evidência de nitritos. Fez radiografia do tórax que não apresentou alterações pleuroparenquimatosas agudas. Realizou tomografia computorizada (TC) abdominopélvica sem contraste que não apresentou alterações. O eletrocardiograma não apresentou alterações.

Assumiu-se cistite aguda, colheu urocultura e iniciou empiricamente amoxicilina-clavulanato.

Por persistência do quadro de febre, calafrios e mialgias, volta ao AP passado uma semana.

Negava anorexia, perda ponderal, dor suprapúbica, lombalgia, queixas urinárias irritativas ou obstrutivas, exsudado uretral, queixas do foro respiratório ou gastrintestinal.

À entrada apresentava-se vígil, orientado e colaborante, GCS:15, sem meningismo, eupneico em repouso, SatO2: 97\%, hemodinamicamente estável, FC: 97 bpm, corado, hidratado e anictérico, mantendo TT de $38,4^{\circ} \mathrm{C}$. Não se palpava adenopatias.
A auscultação não apresentou alterações. $\bigcirc$ abdómen estava mole, depressível, indolor à palpação, sem massas ou organomegalias palpáveis, com ruídos hidroaéreos mantidos em timbre e em frequência. Não apresentava edemas periféricos ou sinais de tromboflebite.

Repetiu análises que evidenciaram diminuição da leucocitose para 11 900/mL com 76,7\% de neutrófilos e queda da PCR para $22 \mathrm{mg} / \mathrm{dL}$. A gasimetria arterial em ar ambiente apresentou alcalémia mista ligeira $(\mathrm{pH}$ : 7,46, PaCO2: 35 mmHg, PaO2: 77 mmHg e HCO3: $25 \mathrm{mmol} / \mathrm{L}$ ), velocidade de sedimentação (VS): $95 \mathrm{~mm} / \mathrm{h}$, urina II e PSA normais.

A urocultura que havia colhido aquando da primeira recorrência ao AP foi negativa. Ficou internado por síndrome febril de etiologia a esclarecer. Colheu hemoculturas em aerobiose e anaerobiose, serologias e escalou-se antibioterapia empírica para piperacilina-tazobactam.

Ao segundo dia de internamento auscultaram-se fervores crepitantes no terço médio do hemitórax direito e terço inferior do hemitórax esquerdo, pelo que se solicitou TC do tórax por suspeita de pneumonia. Contudo, o exame excluiu processo inflamatório ou infecioso agudo, assim como lesões neoformativas, adenopatias ou derrame pleural.

Obtivemos as serologias para Brucella, Salmonella e riquetsioses que foram negativas, mantendo-se a serologia para Coxiella burnetti e as hemoculturas em curso.

Realizou ecocardiograma transtorácico que não apresentou alterações, nomeadamente vegetações ou lesões abcedadas. Solicitou-se ecografia abdominal que mostrou (Fig. 1): "Fígado de dimensões dentro da normalidade, de contornos regulares, apresentando uma ecoestrutura levemente heterogénea de forma difusa. Observa-se formação de configuração ovoide, com cerca de 55 mm, junto à confluência das supra-hepáticas, entre a veia supra-hepática direita e média, de natureza predominantemente quística não pura, achados a merecer estreita integração no contexto clínico-laboratorial examinado, sugerindo-se ponderação de esclarecimento por estudo TC com contraste (formação abcedada? Outra etiologia?)."

Nesse sentido fez TC abdominal com contraste, ao terceiro dia de internamento: "Observamos imagem compatível com abcesso hepático ao nível retro e supra-hilar entre os segmentos VII e I com 6,5 × 6,5 × 6,5 cm, condicionando algum edema do tecido parenquimatoso hepático envolvente, sem compromisso aparente do hilo hepático e sem condicionar ectasia das vias biliares. $\bigcirc$ fígado está normodimensionado, tem contornos regulares e não apresenta outras imagens de lesão ocupando espaço. Pâncreas, baço, áreas suprarrenais e rins sem alterações relevantes. Não há segmentos estenosados ou 
dilatados do tubo digestivo. Não há adenomegalias parietais ou viscerais das cadeias em presença nem ascite."

Confirmado o abcesso hepático iniciou antibioterapia de largo espectro com meropenem.

Solicitou-se avaliação pela Cirurgia Geral e contactou-se a Imagiologia de Intervenção do Hospital CUF Descobertas para se realizar drenagem percutânea.

Acrescentaram-se serologias para VIH 1 e 2, hepatites, Borrelia, Echinococcus, Entamoeba, VDRL (venereal disease research laboratory) e alfa-feto proteína (AFP).

Ao sexto dia de internamento, correspondente ao terceiro dia de meropenem (D3), estando apirético há 72 horas, colocou-se drenagem percutânea ecoguiada no $10^{\circ}$ espaço intercostal direito, tendo-se drenado $60 \mathrm{cc}$ de líquido seropurulento. Colheram-se amostras para culturas em aerobiose, anaerobiose e pesquisa de mycobacterium. As serologias para VIH 1 e 2, sífilis, hepatites e febre Q foram negativas, e a AFP estava dentro dos parâmetros da normalidade. A PCR evoluíra em decrescendo para $12 \mathrm{mg} / \mathrm{dL}$.

Ao nono dia de internamento recebemos o resultado das hemoculturas e a serologia para febre Q que foram negativas. A PCR continuava em curva descendente (10 mg/dL).

No dia seguinte soubemos o resultado das serologias que estavam pendentes: negativas para borreliose e equinococose e positivas para Entamoeba histolytica. Apresentava PCR de 5 mg/dL (sem leucocitose ou neutrofilia), ressalvando-se do ponto de vista analítico, discreta elevação da GGT (109 U/L), da fosfatase alcalina (142 U/L) e diminuição da albumina (2,7 g/dL).

Identificado o agente etiológico, iniciou metronidazol em detrimento de meropenem e fez-se pesquisa de ovos, quistos e parasitas.

Ao $13^{\circ}$ dia de internamento, correspondente ao terceiro dia de metronidazol, houve recidiva da febre após 10 dias de apirexia.

p pico febril coincidiu com recrudescimento da PCR para $8,5 \mathrm{mg} / \mathrm{dL}$, dos restantes reagentes de fase aguda (leucócitos: 16 700/mL, neutrófilos: 87,8\%) e dos parâmetros de citólise hepática (AST: 61 e ALT: 100 U/L).

Ao $14^{\circ}$ dia de internamento, mantinha-se subfebril, fez TC abdómen de controlo (Fig. 2): "Identifica-se uma área de hipodensidade hepática, com dreno, que mede aproximadamente $4 \mathrm{~cm}$.

A pesquisa de ovos, quistos e parasitas foi negativa. A PCR subira para 16 mg/dL, sem alterações do leucograma e a VS era de $65 \mathrm{~mm} / \mathrm{h}$ quando tinha caído para 25 mm/h uma semana antes. Realizou TC CE que não apresentou alterações, nomeadamente lesões abcedadas.
No mesmo dia obteve-se o resultado do isolamento do conteúdo drenado: E. coli sensível a penicilinas, ciprofloxacina, cefuroxima, meropenem, gentamicina e SMX-TMP. Assumiu-se abcesso amebiano sobreinfetado, pelo que se associou ciprofloxacina ao metronidazol, mantendo dreno pigtail por sugestão da Cirurgia Geral.

A febre cedeu e verificou-se normalização das alterações laboratoriais, tendo sido transferido para um hospital público, a pedido do doente, ao $17^{\circ}$ dia de internamento.

Após alta do hospital público continuou a ser seguido, em consulta de Medicina, na nossa Unidade, tendo repetido serologias para Entamoeba histolytica que se mantiveram negativas, verificando-se restitutio ad integrum.

\section{DISCUSSÃO}

A síndrome febril indeterminada, definida como febre com duração superior a três semanas, sem etiologia clarificada após pelo menos uma semana de investigação, 1,2 representa um exercício diagnóstico aliciante pela multiplicidade de diagnósticos possíveis.

Ao longo do tempo têm-se assistido a um aumento da prevalência das patologias inflamatórias (estimando-se que possam ser responsáveis por cerca de 15\% a 25\%

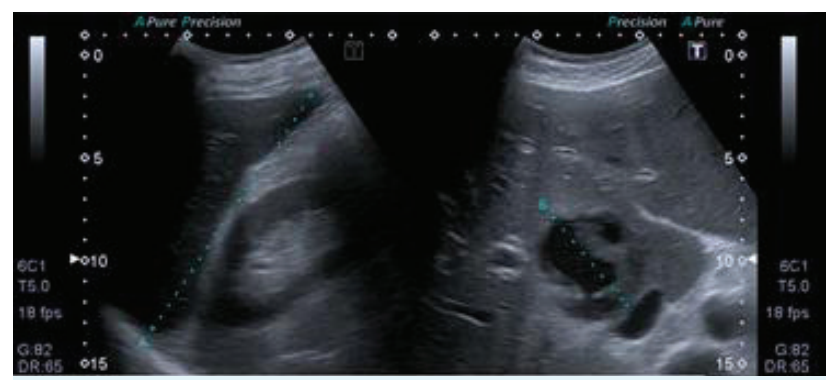

FIGURA 1. Ecografia abdominal mostrando lesão hepática entre os segmentos VII e I.

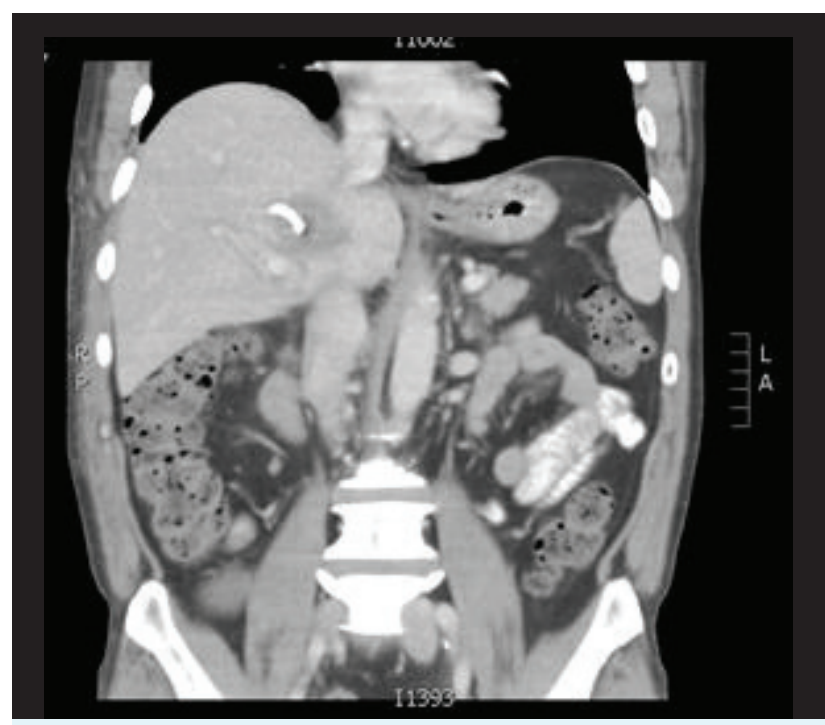

FIGURA 2. TC abdominal evidenciando abcesso hepático com dreno percutâneo. 
dos casos) e uma diminuição das infeções (representando cerca de $15 \%$ a $25 \%$ dos casos) e dos processos neoplásicos (causa subjacente em até 20\%). ${ }^{1-4}$ Em algumas séries o diagnóstico permanece em aberto em cerca de $50 \%$ dos casos. ${ }^{3}$

Atendendo a que o doente não apresentava sintomas sugestivos de um quadro consumptivo, tais como adinamia, astenia, anorexia, perda ponderal, quebra significativa do estado geral, optou-se por relegar a hipótese de processo neoplásico para um segundo plano.

Em virtude da clínica pouco florida, sem qualquer sintoma para além da febre, descartou-se a patologia autoimune como hipotética causa.

O hipertiroidismo pode cursar com febre, porém o doente não apresentava sintomas sugestivos de tirotoxicose, nomeadamente irritabilidade, intolerância ao calor, tremor fino, palpitações, aumento de apetite, diarreia.

A disfunção hipotalâmica, condicionando um compromisso da termorregulação afigurava-se como uma suspeita remota, visto não haver história de traumatismo cranioencefálico ou patologia vascular cerebral.

As síndromes periódicas, tais como a febre mediterrânica familiar, a síndrome periódica associada ao fator de necrose tumoral tipo 1 (TRAPS) ou a síndrome de Muckle-Wells, são hipóteses meramente académicas, pela sua raridade, idade de apresentação e ausência de história familiar.

No caso explanado considerou-se que a causa subjacente mais consistente seria de etiologia infeciosa, e excluídas as infeções mais comuns, assim como a endocardite bacteriana, uma frequente causa de síndrome febril indeterminada, equacionou-se o abcesso hepático, confirmado imagiologicamente. Identificada a causa da febre urgia encontrar o primum movens.

Apesar da amebíase não ser uma entidade nosológica frequente em Portugal, não foi negligenciada por se tratar de uma causa frequente de abcesso hepático, principalmente quando há história de atividade ao ar livre.

Na maioria dos casos de abcesso amebiano a terapêutica com metronidazol é suficiente, ${ }^{5-7}$ neste caso particular optou-se pela drenagem percutânea em virtude das dimensões do abcesso.

De notar que o quadro foi agravado de sobreinfeção a $E$. coli com ponto de partida numa cistite aguda.

Enfatizamos a importância de excluir abcessos ocultos da cavidade abdominal e pélvica, nomeadamente hepáticos, nos quadros em que não se apura um foco séptico categórico.

O célere reconhecimento do abcesso amebiano é crucial atendendo à mortalidade estimada em cerca de 5\%.,8
CONFLITOS DE INTERESSE: Os autores declaram não ter qualquer conflito de interesse na realização do presente trabalho.

FONTES DE FINANCIAMENTO: Não houve qualquer fonte de financiamento na realização do presente trabalho.

CONFIDENCIALIDADE DOS DADOS: Os autores declaram ter seguido os protocolos da sua instituição acerca da publicação dos dados de doentes.

PROTEÇÃO DE PESSOAS E ANIMAIS: Os autores declaram que os procedimentos seguidos na elaboração do presente trabalho estão em conformidade com as normas das comissões de investigação clínica e de ética, bem como da declaração de Helsínquia e da Associação Médica Mundial.

CONFLICTS OF INTEREST: The authors declare that they have no conflicts of interest.

FINANCIAL SUPPORT: This work has not received any contribution, grant or scholarship.

CONFIDENTIALITY OF DATA: The authors declare that they have followed the protocols of their work center on the publication of data from patients.

PROTECTION OF HUMAN AND ANIMAL SUBJECTS: The authors declare that the procedures followed were in accordance with the regulations of the relevant clinical research ethics committee and with those of the Code of Ethics of the World Medical Association (Declaration of Helsinki).

\section{REFERÊNCIAS}

1. Petersdorf RG, Beeson PB. Fever of unexplained origin: report on 100 cases. Medicine. 1961;40:1-30.

2. de Kleijn EM, Vandenbroucke JP, van der Meer JW. Fever of unknown origin (FUO). I A. prospective multicenter study of 167 patients with FUO, using fixed epidemiologic entry criteria. The Netherlands FUO Study Group. Medicine. 1997;76:392-400.

3. Tu JC, Zhou P, Li XJ, Sun Y, Si HY, Wang CW, et al. Clinical Etiologies of Fever of Unknown Origin in 500 Cases. Zhongguo Yi Xue Ke Xue Yuan Xue Bao. 2015;37:348-51.

4. likuni Y, Okada J, Kondo H, Kashiwazaki S. Current fever of unknown origin 1982-1992. Intern Med. 1994;33:67-73.

5. Nespola B, Betz V, Brunet J, Gagnard JC, Krummel Y, Hansmann $Y$, et al. First case of amebic liver abscess 22 years after the first occurrence. Parasite. 2015;22:20.

6. Aucott JN, Ravdin JI. Amebiasis and "nonpathogenic" intestinal protozoa. Infect Dis Clin North Am. 1993;7:467-85.

7. Chaudhary S, Noor MT, Jain S, Kumar R, Thakur BS. Amoebic liver abscess: a report from central India. Trop Doct. 2016;46:12-5.

8. Alam F, Salam MA, Hassan P, Mahmood I, Kabir M, Haque R. Amebic liver abscess in northern region of Bangladesh: sociodemographic determinants and clinical outcomes. BMC Res Notes. 2014;7:625. 